\title{
Inhibition of the low- $K_{\mathrm{m}}$ mitochondrial aldehyde dehydrogenase by diethyl maleate and phorone in vivo and in vitro
}

\author{
Implications for formaldehyde metabolism
}

\author{
Elisa DICKER and Arthur I. CEDERBAUM* \\ Department of Biochemistry, Mount Sinai School of Medicine, New York, NY 10029, U.S.A.
}

\begin{abstract}
Formaldehyde can be oxidized primarily by two different enzymes, the low- $K_{\mathrm{m}}$ mitochondrial aldehyde dehydrogenase and the cytosolic GSH-dependent formaldehyde dehydrogenase. Experiments were carried out to evaluate the effects of diethyl maleate or phorone, agents that deplete GSH from the liver, on the oxidation of formaldehyde. The addition of diethyl maleate or phorone to intact mitochondria or to disrupted mitochondrial fractions produced inhibition of formaldehyde oxidation. The kinetics of inhibition of the low- $K_{\mathrm{m}}$ mitochondrial aldehyde dehydrogenase were mixed. Mitochondria isolated from rats treated in vivo with diethyl maleate or phorone had a decreased capacity to oxidize either formaldehyde or acetaldehyde. The activity of the low- $K_{\mathrm{m}}$, but not the high- $K_{\mathrm{m}}$, mitochondrial aldehyde dehydrogenase was also inhibited. The production of $\mathrm{CO}_{2}$ plus formate from $0.2 \mathrm{mM}-\left[{ }^{14} \mathrm{C}\right]$ formaldehyde by isolated hepatocytes was only slightly inhibited (15-30\%) by incubation with diethyl maleate or addition of cyanamide, suggesting oxidation primarily via formaldehyde dehydrogenase. However, the production of $\mathrm{CO}_{2}$ plus formate was increased 2.5-fold when the concentration of $\left[{ }^{14} \mathrm{C}\right]$ formaldehyde was raised to $1 \mathrm{~mm}$. This increase in product formation at higher formaldehyde concentrations was much more sensitive to inhibition by diethyl maleate or cyanamide, suggesting an important contribution by mitochondrial aldehyde dehydrogenase. Thus diethyl maleate and phorone, besides depleting GSH, can also serve as effective inhibitors in vivo or in vitro of the low- $K_{\mathrm{m}}$ mitochondrial aldehyde dehydrogenase. Inhibition of formaldehyde oxidation by these agents could be due to impairment of both enzyme systems known to be capable of oxidizing formaldehyde. It would appear that a critical amount of GSH, e.g. $90 \%$, must be depleted before the activity of formaldehyde dehydrogenase becomes impaired.
\end{abstract}

\section{INTRODUCTION}

Formaldehyde can be metabolized primarily by two different pathways, one involving oxidation by the low- $K_{\mathrm{m}}$ mitochondrial aldehyde dehydrogenase, the other requiring a specific cytosolic GSH-dependent formaldehyde dehydrogenase (Strittmatter \& Ball, 1955; Goodman \& Tephly, 1971; Uotila \& Koivusalo, 1974; Koivula \& Koivusalo, 1975; Cinti et al., 1976; Siew et al., 1976). More recent experiments (Dicker \& Cederbaum, $1984 a, b)$ have demonstrated that the oxidation of formaldehyde by intact hepatocytes was inhibited by $30-50 \%$ by cyanamide, a potent inhibitor of the low- $K_{\mathrm{m}}$ mitochondrial aldehyde dehydrogenase, or by competitive aldehyde substrates such as acetaldehyde or crotonaldehyde. Cyanamide or acetaldehyde inhibited formaldehyde oxidation by isolated mitochondria but not that by the GSH-dependent formaldehyde dehydrogenase (Dicker \& Cederbaum, 1984a), suggesting that both the mitochondrial and cytosolic formaldehyde dehydrogenases can contribute towards the overall oxidation of formaldehyde by rat hepatocytes. Since the above suggestion was derived from experiments employing inhibitors of the mitochondrial pathway, it was of interest to characterize the quantitative roles played by the two enzyme pathways by attempting to block the cytosolic pathway. Towards this end, experiments were conducted to remove the essential GSH cofactor for the formaldehyde dehydrogenase. Diethyl maleate (DEM) and phorone are agents used to deplete GSH from the liver after treatment in vivo or in vitro (Boyland \& Chausseaud, 1970; Richardson \& Murphy, 1975; Meredith \& Reed, 1982; Romero et al., 1984; Ku \& Billings, 1984). Indeed, several reports have shown that the oxidation of formaldehyde could be decreased after treatment with DEM (Ku \& Billings, 1984; Jones et al., 1978; Savanije-Chapel \& Noordhook, 1980; Bhatt \& Combes, 1985). However, it is unclear which of the enzyme pathways responsible for the oxidation of formaldehyde may have been altered by the DEM treatment, since addition of DEM to hepatocytes or to isolated mitochondria caused inhibition of the oxidation of acetaldehyde (Dicker \& Cederbaum, 1985). This suggested that DEM, besides removing GSH, may also inhibit the low- $K_{\mathrm{m}}$ mitochondrial aldehyde dehydrogenase. Therefore experiments were carried out to evaluate the effects of DEM and phorone in vivo and in vitro on the oxidation of formaldehyde by intact hepatocytes, mitochondria and the cytosolic formaldehyde dehydrogenase.

\section{MATERIALS AND METHODS}

\section{Treatment in vivo}

Male Sprague-Dawley rats ( $250 \mathrm{~g}$ body wt.) were injected intraperitoneally with either DEM (Aldrich 
Chemical Co.; $450 \mu \mathrm{mol} / 100 \mathrm{~g}$ body wt.) or phorone (Aldrich Chemical Co.; $180 \mu \mathrm{mol} / 100 \mathrm{~g}$ body wt.) as described by Bhatt \& Combes (1985). Controls received intraperitoneal injections of corn oil. For most of the studies performed in vitro, mitochondria, cytosolic fractions and hepatocytes were prepared from chow-fed control rats.

\section{Mitochondrial studies}

Rats were killed $60 \mathrm{~min}$ after injection, and liver mitochondria were prepared as described previously (Cederbaum, 1981). The oxidation of formaldehyde was determined at $37^{\circ} \mathrm{C}$ with a reaction system containing $0.25 \mathrm{M}$-sucrose, $3.3 \mathrm{~mm}-\mathrm{MgCl}_{2}, 10 \mathrm{~mm}$-potassium phosphate buffer, $\mathrm{pH} 7.4,3.3 \mathrm{~mm}-\mathrm{ADP}$ and $3-5 \mathrm{mg}$ of mitochondrial protein in a final volume of $3 \mathrm{ml}$. In some experiments mitochondria from chow-fed rats were incubated with either DEM, phorone or $0.5 \%(\mathrm{v} / \mathrm{v})$ dimethyl sulphoxide (solvent for the DEM or phorone) for $10 \mathrm{~min}$ before the reaction was started with formaldehyde (final concentration $1.0 \mathrm{~mm}$ ). Reactions were terminated after 5-10 min by the addition of trichloroacetic acid to a final concentration of $4.5 \%$ $(w / v)$. The remaining formaldehyde was determined on portions of the trichloroacetic acid supernatant by the method of Nash (1953). Zero-time controls contained the trichloroacetic acid added before the mitochondria and were used to correct for non-specific binding of formaldehyde.

The oxidation of $0.2 \mathrm{~mm}$-acetaldehyde by mitochondria was carried out essentially as described above for formaldehyde, except that $\mathrm{HCl}$ was utilized to terminate reactions and the remaining acetaldehyde was detected by a head-space gas-chromatography procedure (Dicker $\&$ Cederbaum, 1985). The activity of aldehyde dehydrogenase was determined as previously described (Dicker \& Cederbaum, 1984b). The enzyme mixture was incubated with dimethyl sulphoxide, phorone or DEM for $10 \mathrm{~min}$ before the addition of various concentrations of formaldehyde, and the change of absorbance at $340 \mathrm{~nm}$ was recorded.

\section{Cytosolic studies}

Homogenates were prepared in $0.25 \mathrm{M}$-sucrose/

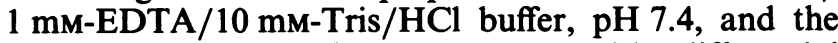
$100000 \mathrm{~g}$ cytosolic fraction was prepared by differential centrifugation. Assays were conducted at room temperature in a $3 \mathrm{ml}$ reaction system containing $100 \mathrm{~mm}$-sodium pyrophosphate buffer, $\mathrm{pH} 8.0,0.67 \mathrm{~mm}-\mathrm{NAD}^{+}, 3 \mathrm{~mm}-$ pyrazole and about $5 \mathrm{mg}$ of cytosolic protein. To assay the activity of the high- $K_{\mathrm{m}}$ cytosolic aldehyde dehydrogenase, 5 mM-acetaldehyde was employed as the substrate. Formaldehyde dehydrogenase activity was determined with $1 \mathrm{~mm}$-formaldehyde in the presence of endogenous GSH of the cytosol or in the presence of GSH added to a final concentration of $2 \mathrm{~mm}$. The change in absorbance at $340 \mathrm{~nm}$ was measured for $2-3 \mathrm{~min}$ before the addition of the aldehyde substrate.

In some experiments, cytosolic fractions prepared from chow-fed control rats were dialysed overnight

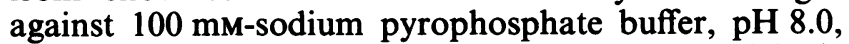
to remove endogenous GSH. Rates of formaldehyde ( $1 \mathrm{mM}$ ) oxidation were determined for 2-3 min, various concentrations of GSH were then added, and the net change in absorbance at $340 \mathrm{~nm}$ was recorded.
Table 1. Effect of addition of DEM and phorone in vitro on mitochondrial oxidation of formaldehyde

The oxidation of $1 \mathrm{~mm}$-formaldehyde by intact rat liver mitochondria isolated from chow-fed control rats was assayed as described in the Materials and methods section. Mitochondria were incubated with dimethyl sulphoxide, DEM or phorone for $10 \mathrm{~min}$. Results are from three experiments. Significance of difference: ${ }^{*} P<0.05$; $\dagger P<0.01$

\begin{tabular}{lc}
\hline & $\begin{array}{c}\text { Oxidation of } \\
\text { formaldehyde } \\
\text { (nmol/min per } \mathrm{mg} \\
\text { of mitochondrial } \\
\text { protein) }\end{array}$ \\
\hline \multicolumn{1}{c}{ Addition } & $9.86 \pm 1.11$ \\
Dimethyl sulphoxide $(0.5 \%)$ & $6.10 \pm 0.66^{*}$ \\
DEM (0.2 $\mathrm{mM})$ & $3.02 \pm 0.66 \dagger$ \\
DEM (1.0 $\mathrm{mM})$ & $6.05 \pm 0.98^{*}$ \\
Phorone $(0.5 \mathrm{mM})$ &
\end{tabular}

\section{Experiments with hepatocytes}

Hepatocytes were isolated from chow-fed male Sprague-Dawley rats $(250-300 \mathrm{~g})$ as described previously (Cederbaum et al., 1977). The liver cells were suspended in Krebs-Ringer bicarbonate/10 mM-phosphate buffer, pH 7.4 (Umbreit et al., 1959), supplemented with $1.25 \%$ (w/v) fatty acid-free bovine serum albumin saturated with $\mathrm{O}_{2} / \mathrm{CO}_{2}(19: 1)$. The hepatocytes were incubated with $1 \mathrm{mM}$-DEM or $0.5 \%$ dimethyl sulphoxide for $60 \mathrm{~min}$. After this period, one portion of each, the DEM-treated or the dimethyl sulphoxide control cells, was washed twice with Krebs-Ringer buffer and resuspended in fresh medium in order to remove the DEM or dimethyl sulphoxide. These portions are referred to as DEM-washed cells. Other portions were used directly without washing; these are referred to as DEM-not-washed cells. Under these conditions the treatment with $1 \mathrm{mM}$-DEM for $60 \mathrm{~min}$ decreased the content of GSH from a control value of 6.35 to a value of $1.6 \mu \mathrm{mol} / \mathrm{g}$ wet wt. of liver for the DEM-treated cells. The oxidation of formaldehyde to $\mathrm{CO}_{2}$ plus formate by the various hepatocyte portions was assayed as previously described (Dicker \& Cederbaum, 1984a). Methionine was added at a concentration of $0.4 \mathrm{~mm}$ to promote oxidation of formate to $\mathrm{CO}_{2}$ (Krebs et al., 1976; Billings \& Tephly, 1979). Reactions were initiated by the addition of $\left[{ }^{14} \mathrm{C}\right]$ formaldehyde at a final concentration of either 0.2 or $1.0 \mathrm{~mm}$, and final specific radioactivity $0.083 \mu \mathrm{Ci} / \mu \mathrm{mol}$, and terminated after 5,10 or $20 \mathrm{~min}$ by the addition of $\mathrm{HCl}$ (final concentration $0.25 \mathrm{M}$ ). $\mathrm{CO}_{2}$ was collected in centre-well cups and its radioactivity was determined. The material remaining in the flasks was then assayed for formate by a formate dehydrogenase procedure (Billings \& Tephly, 1979).

All values represent means \pm S.E.M. Statistical analyses were performed by Student's $t$ test.

\section{RESULTS}

Effects of DEM and phorone in vitro on mitochondrial oxidation of formaldehyde

Isolated intact rat liver mitochondria oxidized $1 \mathrm{~mm}$ formaldehyde at a rate of about $10 \mathrm{nmol} / \mathrm{min}$ per $\mathrm{mg}$ of 


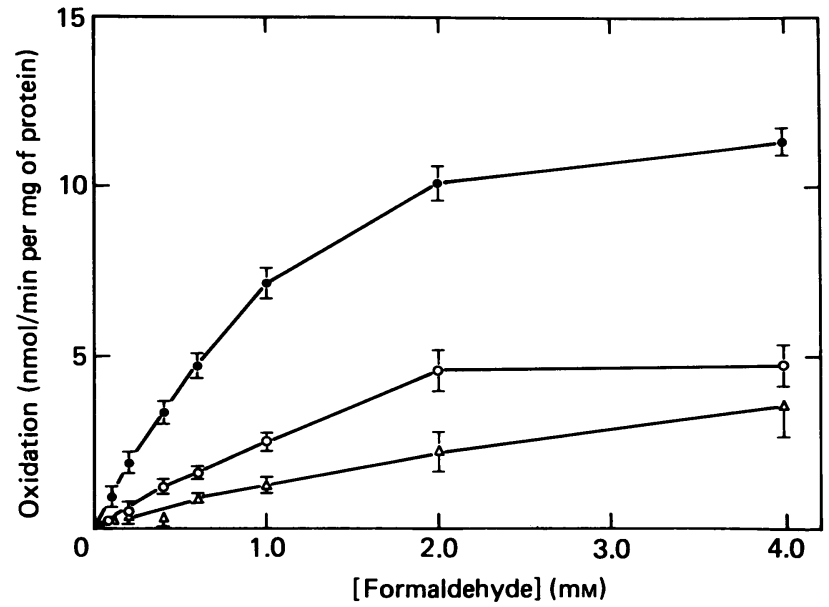

Fig. 1. Substrate concentration plot of the effect of the addition of DEM and phorone in vitro on mitochondrial aldehyde dehydrogenase activity

The oxidation of various concentrations of formaldehyde by disrupted mitochondria was assayed in the absence (O) and in the presence of $1 \mathrm{~mm}-\mathrm{DEM}(\mathrm{O})$ or $1 \mathrm{~mm}$-phorone $(\triangle)$. Results are from three experiments.

protein (Table 1). Mitochondria that had been incubated with phorone or DEM for 10 min showed a decreased capacity to oxidize formaldehyde as compared with controls that had been incubated with dimethyl sulphoxide (Table 1).

The oxidation of formaldehyde by disrupted mitochondria in the presence of excess $\mathrm{NAD}^{+}$was assayed to assess the effects of DEM and phorone on aldehyde dehydrogenase activity. The oxidation of formaldehyde increased over the range 0.1-2 mM-formaldehyde (Fig. 1). At all concentrations of formaldehyde tested, DEM and phorone were potent inhibitors of formaldehyde oxidation (Fig. 1). Over the substrate range 0.1-4 mMformaldehyde, Lineweaver-Burk plots were linear for control samples (incubated with dimethyl sulphoxide). Lineweaver-Burk plots for samples treated with DEM or phorone were linear over the formaldehyde substrate range of either $0.4-4 \mathrm{~mm}$ or $0.6-4 \mathrm{~mm}$, and this range of substrate concentrations was utilized to evaluate kinetic constants. The kinetics of inhibition by DEM and phorone were complex, as $K_{\mathrm{m}}$ values were calculated to be $1.5,3.1$ and $4.1 \mathrm{~mm}$ for controls, DEM-treated or phorone-treated samples respectively, whereas $V_{\max }$. values were $17.4,10.3$ and $7.2 \mathrm{nmol} / \mathrm{min}$ per $\mathrm{mg}$ of mitochondrial protein for controls, DEM-treated and phorone-treated samples respectively. Thus both inhibitors raised the $K_{\mathrm{m}}$ for formaldehyde while decreasing $V_{\max }$. Although the kinetics were mixed, DEM appeared to have a large non-competitive component associated with the inhibition of formaldehyde oxidation.

\section{Treatment with DEM and phorone in vivo}

The content of GSH in liver homogenates or $100000 \mathrm{~g}$ supernatant fractions was depleted by about $90 \%$ after treatment with DEM or phorone in vivo. The mitochondrial content of GSH was lowered by about $40 \%$. The greater depletion of cytosolic than of mitochondrial GSH content has been observed by others (Meredith \& Reed, 1982; Romero et al., 1984). Mitochondria isolated from corn-oil controls oxidized formaldehyde and acetaldehyde at rates of about 15 and $25 \mathrm{nmol} /$ min per mg of protein respectively (Table 2). The rate of oxidation of formaldehyde and acetaldehyde was decreased by more than $80 \%$ in mitochondria isolated from rats treated with DEM. Treatment with phorone in vivo at the dosage utilized was less effective than DEM in inhibiting the oxidation of the aldehydes (Table 2). The residual rate of formaldehyde and acetaldehyde oxidation by mitochondria isolated after phorone treatment was very sensitive to inhibition by cyanamide.

The oxidation of $2 \mathrm{~mm}$-formaldehyde or $0.2 \mathrm{~mm}$ acetaldehyde by disrupted mitochondria was decreased after treatment with DEM or phorone in vivo (Table 3). Unlike formaldehyde, acetaldehyde, besides serving as a substrate for the low $-K_{\mathrm{m}}$ mitochondrial aldehyde dehydrogenase, can also serve as a substrate for the high- $K_{\mathrm{m}}$ mitochondrial aldehyde dehydrogenase (Koivula \& Koivusalo, 1975; Siew et al., 1976; Lesback et al., 1977). Total aldehyde dehydrogenase activity was assayed by using an acetaldehyde concentration of $5 \mathrm{~mm}$; the difference between the aldehyde dehydrogenase activities at $5 \mathrm{~mm}$ - and $0.2 \mathrm{~mm}$-acetaldehyde was taken as a reflection of the high- $K_{m}$ aldehyde dehydrogenase activity. Treatment with DEM or phorone resulted in a $25 \%$ decrease in activity of the high- $K_{\mathrm{m}}$ aldehyde dehydrogenase. This decrease was less than the decrease

\section{Table 2. Effect of treatment with DEM and phorone in vivo on mitochondrial oxidation of formaldehyde and acetaldehyde}

Rats were injected with corn oil, DEM or phorone as described in the Materials and methods section. Mitochondria were isolated $60 \mathrm{~min}$ later, and the oxidation of $1 \mathrm{mM}$-formaldehyde or $0.2 \mathrm{~mm}$-acetaldehyde was assayed in the absence and in the presence of $0.1 \mathrm{~mm}$-cyanamide. Results are from three experiments for each treatment. Significance of difference: ${ }^{*} P<0.001$; $\dagger P<0.005 ; \ddagger P<0.05$.

\begin{tabular}{|c|c|c|c|c|c|}
\hline \multirow[b]{2}{*}{ Substrate } & \multirow[b]{2}{*}{ Treatment } & \multicolumn{2}{|c|}{$\begin{array}{l}\text { Aldehyde oxidation (nmol/min per mg } \\
\text { of mitochondrial protein) }\end{array}$} & \multirow{2}{*}{$\begin{array}{c}\text { Effect of } \\
\text { treatment } \\
(\%)\end{array}$} & \multirow{2}{*}{$\begin{array}{c}\text { Effect of } \\
\text { cyanamide } \\
(\%)\end{array}$} \\
\hline & & - Cyanamide & + Cyanamide & & \\
\hline Formaldehyde & $\begin{array}{l}\text { Corn oil } \\
\text { DEM } \\
\text { Phorone }\end{array}$ & $\begin{array}{r}15.59 \pm 1.69 \\
3.00 \pm 1.13 \\
9.93 \pm 0.95\end{array}$ & $\begin{array}{l}1.44 \pm 0.27 \\
1.38 \pm 0.76 \\
0.59 \pm 0.10\end{array}$ & $\begin{array}{l}-\overline{81} \\
-36 \dagger\end{array}$ & $\begin{array}{l}-91^{*} \\
-54 \\
-94^{*}\end{array}$ \\
\hline Acetaldehyde & $\begin{array}{l}\text { Corn oil } \\
\text { DEM } \\
\text { Phorone }\end{array}$ & $\begin{array}{r}25.14 \pm 1.04 \\
2.78 \pm 0.24 \\
17.59 \pm 1.80\end{array}$ & $\begin{array}{l}4.10 \pm 0.86 \\
1.06 \pm 0.14 \\
2.37 \pm 0.92\end{array}$ & $\begin{array}{l}-\overline{89 *} \\
-30 \ddagger\end{array}$ & $\begin{array}{l}-84 \dagger \\
-62 \ddagger \\
-87 \dagger\end{array}$ \\
\hline
\end{tabular}


Table 3. Effect of treatment with DEM and phorone in vivo on mitochondrial aldehyde dehydrogenase activities

Rats were injected with corn oil, DEM or phorone. Mitochondria were prepared $60 \mathrm{~min}$ later, and disrupted with deoxycholate. The activity of the low- $K_{\mathrm{m}}$ aldehyde dehydrogenase was assessed with either $2 \mathrm{~mm}$-formaldehyde (A) or 0.2 mM-acetaldehyde (B) as substrate. Total aldehyde dehydrogenase activity was determined with $5 \mathrm{~mm}$-acetaldehyde $(\mathrm{C})$; differences between rates at $5 \mathrm{~mm}$-acetaldehyde minus the rates at $0.2 \mathrm{~mm}$-acetaldehyde $(C-B)$ were taken as the activity of the high- $K_{m}$ aldehyde dehydrogenase of mitochondria (D). Results are from three experiments for each treatment. Significance of difference: ${ }^{*} P<0.005 ;+P<0.05$.

\begin{tabular}{|c|c|c|}
\hline Substrate & Treatment & $\begin{array}{c}\text { Aldehyde } \\
\text { oxidation } \\
\text { (nmol/min per mg } \\
\text { of mitochondrial } \\
\text { protein) }\end{array}$ \\
\hline A. Formaldehyde ( $2 \mathrm{~mm})$ & $\begin{array}{l}\text { Corn oil } \\
\text { DEM } \\
\text { Phorone }\end{array}$ & $\begin{array}{l}7.06 \pm 1.28 \\
0.51 \pm 0.03^{*} \\
3.76 \pm 0.52 \dagger\end{array}$ \\
\hline B. Acetaldehyde (0.2 mM) & $\begin{array}{l}\text { Corn oil } \\
\text { DEM } \\
\text { Phorone }\end{array}$ & $\begin{array}{c}12.36 \pm 0.28 \\
2.06 \pm 0.07^{*} \\
5.80 \pm 0.77^{*}\end{array}$ \\
\hline C. Acetaldehyde (5 mM) & $\begin{array}{l}\text { Corn oil } \\
\text { DEM } \\
\text { Phorone }\end{array}$ & $\begin{array}{l}25.64 \pm 2.01 \\
11.96 \pm 0.96^{*} \\
13.96 \pm 1.10^{*}\end{array}$ \\
\hline $\begin{array}{l}\text { D. Acetaldehyde } \\
\text { (5 mM minus } 0.2 \mathrm{~mm} \text { ) }\end{array}$ & $\begin{array}{l}\text { Corn oil } \\
\text { DEM } \\
\text { Phorone }\end{array}$ & $\begin{array}{r}13.28 \pm 1.78 \\
9.70 \pm 1.03 \\
9.67 \pm 0.88\end{array}$ \\
\hline
\end{tabular}

in activity of the low- $K_{\mathrm{m}}$ aldehyde dehydrogenase (Table 3).

The effect of a $10 \mathrm{~min}$ incubation period with $1 \mathrm{mM}$-DEM or $0.5 \mathrm{mM}$-phorone in vitro on the activity of the high- $K_{\mathrm{m}}$ enzyme was tested. Disrupted mitochondria from corn-oil-treated rats were utilized for these experiments. The addition of DEM and phorone in vitro had no effect on the activity of the high- $K_{\mathrm{m}}$ aldehyde dehydrogenase (rates were $26.6 \pm 3.6$ for controls, $24.7 \pm 1$ for DEM-incubated and $26.8 \pm 3.2 \mathrm{nmol}$ of acetaldehyde/min per $\mathrm{mg}$ of protein for phorone-incubated, $n=3$ ). Under these conditions, the activity of the low- $K_{\mathrm{m}}$ aldehyde dehydrogenase was inhibited by $55 \%$ (1 mM-DEM) or $42 \%$ (0.5 mM-phorone) when $2 \mathrm{mM}$ formaldehyde was the substrate and by $51 \%$ (DEM) or $34 \%$ (phorone) when $0.2 \mathrm{~mm}$-acetaldehyde was the substrate.

\section{Effects of DEM and phorone in vivo and in vitro on cytosolic aldehyde dehydrogenases}

Soluble supernatant fractions were prepared from rats treated with DEM or phorone or corn oil controls and the oxidation of $5 \mathrm{~mm}$-acetaldehyde was studied. As was found in the mitochondrial studies, the activity of the high- $K_{\mathrm{m}}$ aldehyde dehydrogenase of the cytosol was only slightly affected by treatment with DEM or phorone in vivo (Table 4).

Treatment with DEM or phorone in vivo resulted in a $40-50 \%$ decrease in the activity of the GSH-dependent formaldehyde dehydrogenase when assays were conducted in the absence of added GSH (Table 4). The addition
Table 4. Effect of treatment with DEM and phorone in vivo on cytosolic aldehyde dehydrogenase activities

Rats were injected with corn oil, DEM or phorone as described in the Materials and methods section. Cytosolic fractions were prepared $60 \mathrm{~min}$ later and assayed for either high- $K_{\mathrm{m}}$ aldehyde dehydrogenase with $5 \mathrm{~mm}$-acetaldehyde as substrate or for formaldehyde dehydrogenase activity with $2 \mathrm{~mm}$-formaldehyde as substrate. The latter activity was determined in the absence and in the presence of $2 \mathrm{mM}$ added GSH. Results are from three experiments for each treatment. Significance of difference: ${ }^{*} P<0.05$.

\begin{tabular}{lll}
\hline Substrate & Treatment & $\begin{array}{c}\text { Aldehyde oxidation } \\
\text { (nmol/min per mg } \\
\text { of cytosol protein) }\end{array}$ \\
\hline Acetaldehyde & Corn oil & $3.20 \pm 0.38$ \\
& DEM & $2.35 \pm 0.35$ \\
Formaldehyde & Phorone & $2.77 \pm 0.31$ \\
& Corn oil & $3.80 \pm 0.57$ \\
Formaldehyde plus added & DEM & $1.92 \pm 0.58^{*}$ \\
GSH & Phorone & $2.28 \pm 0.37^{*}$ \\
& DEM & $3.93 \pm 0.47$ \\
& Phorone & $3.86 \pm 0.53$ \\
& & $4.48 \pm 0.38$ \\
\hline
\end{tabular}

of GSH had no effect on the rate of formaldehyde oxidation by corn oil control cytosolic fractions, indicating that the amount of endogenous GSH present was sufficient to saturate the enzyme with cofactor. However, the addition of GSH resulted in a 2-fold increase in the rate of formaldehyde oxidation by supernatant fractions isolated from rats treated with DEM or phorone; in the presence of added GSH the activity of formaldehyde dehydrogenase was the same in all three supernatant fractions (Table 4).

The apparent $K_{\mathrm{m}}$ of formaldehyde dehydrogenase for GSH was evaluated after first dialysing overnight the cytosolic fractions isolated from control rats to remove endogenous GSH. In the absence of added GSH there was no oxidation of formaldehyde by dialysed cytosolic fractions (Fig. 2). The activity of formaldehyde dehydrogenase increased as the concentration of GSH increased (Fig. 2). A Lineweaver-Burk plot of these data was linear (Fig. 2 inset); the apparent $K_{\mathrm{m}}$ for GSH was $0.09 \mathrm{~mm}$ and $V_{\max }$. was $5.3 \mathrm{nmol} / \mathrm{min}$ per $\mathrm{mg}$ of supernatant protein.

\section{Oxidation of $\left[{ }^{14} \mathrm{C}\right]$ formaldehyde to ${ }^{14} \mathrm{CO}_{2}$ plus} $\left[{ }^{14} \mathrm{Clformate}\right.$ by isolated hepatocytes

Isolated hepatocytes from chow-fed rats were incubated with dimethyl sulphoxide (control) or 1 mM-DEM for $60 \mathrm{~min}$ at room temperature and either used directly (not-washed samples) or washed twice and resuspended in DEM-free buffer (washed samples). Values of formaldehyde oxidation for dimethyl sulphoxide controls were the same for washed and non-washed samples, and hence all control values were combined. Reactions were linear over a 20 min time course for all experiments. As shown in Table 5 , the rate of production of $\mathrm{CO}_{2}$ and formate from $0.2 \mathrm{~mm}-\left[{ }^{14} \mathrm{C}\right]$ formaldehyde was not significantly affected by the DEM treatment. In control hepatocytes, cyanamide decreased the rates of $\mathrm{CO}_{2}$ and formate production by 20 and $50 \%$ respectively, and total product formation was depressed by about $30 \%$ (Table 5). The results with cyanamide and DEM suggest 


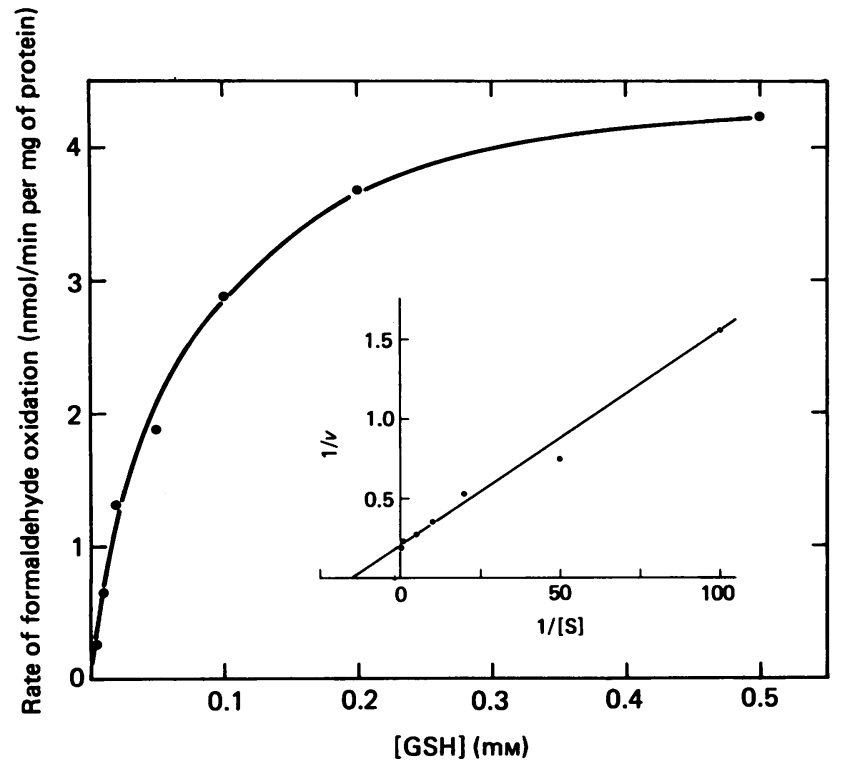

Fig. 2. Cytosolic formaldehyde dehydrogenase activity as a function of the concentration of GSH

Soluble supernatant fractions $(100000 \mathrm{~g}$ supernatants) were dialysed overnight and the oxidation of $1 \mathrm{~mm}$ formaldehyde was studied in the presence of various concentrations of GSH. Results are from three experiments.

that at a concentration of $0.2 \mathrm{~mm}$ most of the formaldehyde is oxidized primarily by formaldehyde dehydrogenase.

At the higher concentration of $1 \mathrm{~mm}$-formaldehyde, rates of $\mathrm{CO}_{2}$ and formate production were increased by 45 and $500 \%$ respectively; total product formation was increased 2.5-fold over that found with $0.2 \mathrm{~mm}$ formaldehyde as the substrate (Table 5). In samples incubated with DEM and subsequently washed, rates of production of $\mathrm{CO}_{2}$, formate and $\mathrm{CO}_{2}$ plus formate were lowered by 25,40 and $33 \%$ respectively. In samples treated with DEM and not washed, the extent of inhibition of $1 \mathrm{~mm}$-formaldehyde oxidation was greater than in the washed samples; rates of production of $\mathrm{CO}_{2}$, formate and $\mathrm{CO}_{2}$ plus formate were lowered by 40,60 and $50 \%$ respectively (Table 5). By comparison, cyanamide lowered the dimethyl sulphoxide control rates of production of $\mathrm{CO}_{2}$, formate and $\mathrm{CO}_{2}$ plus formate by about 60,80 and $70 \%$ respectively (Table 5). Thus DEM and cyanamide were more effective in inhibiting the oxidation of $1 \mathrm{~mm}$-formaldehyde than that of $0.2 \mathrm{~mm}$ formaldehyde. The fact that not only $\mathrm{CO}_{2}$ production but also formate production were decreased by DEM (and by cyanamide) indicates that these agents are inhibiting the oxidation of formaldehyde to formate rather than the oxidation of formate to $\mathrm{CO}_{2}$.

\section{DISCUSSION}

The addition of DEM or phorone in vitro to intact mitochondria, or to disrupted mitochondrial fractions, results in inhibition of formaldehyde oxidation and of the activity of the low- $K_{\mathrm{m}}$ aldehyde dehydrogenase. The high- $K_{\mathrm{m}}$ aldehyde dehydrogenase is less sensitive to inhibition by phorone or DEM. Treatment with DEM or phorone in vivo also results in inhibition of mitochondrial aldehyde dehydrogenase activity and of the oxidation of aldehydes by intact mitochondria. Thus these agents can serve as effective inhibitors in vivo or in vitro of the low- $K_{\mathrm{m}}$ mitochondrial aldehyde dehydrogenase. Inhibition of aldehyde oxidation by intact mitochondria correlates with the extent of inhibition of the low $-K_{\mathrm{m}}$ aldehyde

Table 5. Efiect of DEM on the oxidation of formaldehyde by isolated hepatocytes

Hepatocytes were incubated with either $0.5 \%$ dimethyl sulphoxide $\left(\mathrm{Me}_{2} \mathrm{SO}\right)$ or $1 \mathrm{mM}-\mathrm{DEM}$ for 60 min and then used directly (not washed) or washed twice with buffer. The washing was carried out to remove the presence of DEM from the reaction system and to evaluate reversibility of any inhibition. Values for dimethyl sulphoxide washed or not washed were the same and have been combined. The production of $\mathrm{CO}_{2}$ or formate from either $0.2 \mathrm{mM}$ - or $1.0 \mathrm{~mm}$-formaldehyde was assayed as described in the Materials and methods section. Results are from three or four experiments. Cyanamide when present was added at a final concentration of $0.1 \mathrm{mM}$. Significance of difference: ${ }^{*} P<0.005 ; \dagger P<0.02 ; \ddagger P<0.05$.

\begin{tabular}{|c|c|c|c|c|c|}
\hline \multirow{2}{*}{$\begin{array}{l}\text { Formaldehyde } \\
\qquad(\mathrm{mM})\end{array}$} & \multirow[b]{2}{*}{ Product } & \multirow[b]{2}{*}{ Cyanamide } & \multicolumn{3}{|c|}{$\begin{array}{l}\text { Rate of oxidation of formaldehyde } \\
\text { (nmol/min per mg of cell protein) }\end{array}$} \\
\hline & & & $\mathrm{Me}_{2} \mathrm{SO}$ & DEM-washed & DEM-not-washed \\
\hline \multirow[t]{3}{*}{0.2} & $\mathrm{CO}_{2}$ & $\overline{+}$ & $\begin{array}{l}0.67 \pm 0.02 \\
0.53 \pm 0.05 \ddagger\end{array}$ & $\begin{array}{l}0.58 \pm 0.09 \\
0.43 \pm 0.02\end{array}$ & $\begin{array}{l}0.63 \pm 0.07 \\
0.45 \pm 0.03 \ddagger\end{array}$ \\
\hline & Formate & $\overline{+}$ & $\begin{array}{l}0.25 \pm 0.04 \\
0.09 \pm 0.04 \ddagger\end{array}$ & $\begin{array}{l}0.19 \pm 0.03 \\
0.09 \pm 0.03 \ddagger\end{array}$ & $\begin{array}{l}0.16 \pm 0.03 \\
0.13 \pm 0.03\end{array}$ \\
\hline & $\mathrm{CO}_{2}+$ formate & $\bar{t}$ & $\begin{array}{l}0.91 \pm 0.05 \\
0.65 \pm 0.08 \ddagger\end{array}$ & $\begin{array}{l}0.77 \pm 0.09 \\
0.52 \pm 0.05 \ddagger\end{array}$ & $\begin{array}{l}0.79 \pm 0.07 \\
0.57 \pm 0.01 \ddagger\end{array}$ \\
\hline \multirow[t]{3}{*}{1.0} & $\mathrm{CO}_{2}$ & $\bar{t}$ & $\begin{array}{l}0.95 \pm 0.06 \\
0.39 \pm 0.03^{*}\end{array}$ & $\begin{array}{l}0.72 \pm 0.17 \\
0.48 \pm 0.16\end{array}$ & $\begin{array}{l}0.58 \pm 0.03 \dagger \\
0.40 \pm 0.03 \dagger\end{array}$ \\
\hline & Formate & $\bar{t}$ & $\begin{array}{l}1.52 \pm 0.08 \\
0.32 \pm 0.05^{*}\end{array}$ & $\begin{array}{l}0.94 \pm 0.21 \dagger \\
0.41 \pm 0.13 \ddagger\end{array}$ & $\begin{array}{l}0.63 \pm 0.12^{*} \\
0.39 \pm 0.11\end{array}$ \\
\hline & $\mathrm{CO}_{2}+$ formate & $\overline{+}$ & $\begin{array}{l}2.47 \pm 0.13 \\
0.72 \pm 0.06^{*}\end{array}$ & $\begin{array}{l}1.66 \pm 0.25 \dagger \\
0.87 \pm 0.29 \ddagger\end{array}$ & $\begin{array}{l}1.21 \pm 0.14^{*} \\
0.78 \pm 0.13\end{array}$ \\
\hline
\end{tabular}


dehydrogenase. Kinetic experiments indicate a complex pattern of inhibition, as $K_{\mathrm{m}}$ values for formaldehyde are elevated while $V_{\max }$. values are lowered by the addition of DEM or phorone. The largely non-competitive component of the inhibition kinetics could reflect the known sensitivity of the low- $K_{\mathrm{m}}$ enzyme to a variety of reagents that react with thiol groups (Deitrich \& Hellerman, 1963; Eckfeldt et al., 1976; Kitson, 1977). Aldehyde dehydrogenase contains reactive thiol groups, and DEM and phorone may act like other thiol-blocking reagents that inhibit this enzyme (Weiner et al., 1985; Pietruszko et al., 1985). In view of this inhibition of aldehyde dehydrogenase, experiments with these agents should be interpreted cautiously. For example, peroxidation of lipids results in the production of malondialdehyde and a variety of aldehydes, e.g. propanal, pentanal and hexanal (Poli et al., 1985), that can serve as substrates for aldehyde dehydrogenase. Stimulation of lipid peroxidation by DEM or phorone, besides being a consequence of GSH depletion, may also reflect an inhibition of aldehyde dehydrogenase, with a subsequent increase in the accumulation of aldehydic products.

Formaldehyde can be oxidized by the low- $K_{\mathrm{m}}$ mitochondrial aldehyde dehydrogenase or by the GSHdependent cytosolic formaldehyde dehydrogenase (Strittmatter \& Ball, 1955; Goodman \& Tephly, 1971; Uotila \& Koivusalo, 1974; Koivula \& Koivusalo, 1975; Cinti et al., 1976; Siew et al., 1976). In view of the requirement for GSH, it was reasonable to expect that lowering of the GSH content would decrease the oxidation of formaldehyde by formaldehyde dehydrogenase, and indeed this has been observed (Jones et al., 1978; Romero et al., 1984; Ku \& Billings, 1984). Although effects on the formaldehyde dehydrogenase pathway cannot be ruled out, results given in the present paper suggest that the impairment of oxidation of formaldehyde by DEM may also be a consequence of inhibition of the mitochondrial aldehyde dehydrogenase pathway of formaldehyde oxidation. The addition of DEM or phorone in vitro, or treatment with DEM or phorone in vivo, causes inhibition of formaldehyde oxidation by intact or disrupted mitochondria. The pattern of inhibition of formaldehyde oxidation by DEM was similar to that found with cyanamide. In addition, whereas cyanamide lowered the production of $\mathrm{CO}_{2}$ plus formate from $1 \mathrm{~mm}$-formaldehyde by dimethyl sulphoxide controls by $70 \%$, the inhibition by cyanamide was considerably less for the DEM-not-washed hepatocyte samples. This is probably a reflection of both inhibitors affecting the same enzyme system, i.e. the low- $K_{\mathrm{m}}$ mitochondrial aldehyde dehydrogenase. Bhatt \& Combes (1985) have reported that administration of DEM and phorone in vivo caused a decrease in the production of ${ }^{14} \mathrm{CO}_{2}$ from $\left[{ }^{14} \mathrm{C}\right]$ aminopyrine. Of interest was the observation that a higher dose of phorone $(180 \mu \mathrm{mol} / 100 \mathrm{~g}$ body wt.) was more inhibitory than a lower dose $(90 \mu \mathrm{mol} / 100 \mathrm{~g})$, although the depletion of GSH was identical for both doses (Bhatt \& Combes, 1985). It is possible that a greater extent of inhibition of the mitochondrial aldehyde dehydrogenase by the higher dose of phorone may explain these findings.

The greater sensitivity of $1 \mathrm{~mm}$-formaldehyde oxidation than of a lower concentration such as $0.2 \mathrm{mM}$ to inhibition by DEM or cyanamide is probably a reflection of the higher affinity for formaldehyde of formaldehyde dehydrogenase than that of the low- $K_{\mathrm{m}}$ mitochondrial aldehyde dehydrogenase. The $K_{\mathrm{m}}$ of intact mitochondria for oxidation of formaldehyde was reported to be $0.38 \mathrm{~mm}$ (Cinti et al., 1976); disrupted mitochondria oxidized formaldehyde with an apparent $K_{\mathrm{m}}$ of $1.5 \mathrm{mM}$ (Fig. 2). These values are about an order of magnitude greater than the $K_{\mathrm{m}}$ of $0.06 \mathrm{~mm}$ previously found for the GSH-dependent oxidation of formaldehyde by cytosolic fractions (Dicker \& Cederbaum, 1984a). Therefore it is likely that low concentrations of formaldehyde would be oxidized primarily by formaldehyde dehydrogenase, whereas mitochondrial aldehyde dehydrogenase would become more important in oxidizing higher concentrations of formaldehyde. The net increase in formaldehyde oxidation produced by a higher concentration of formaldehyde was very sensitive to inhibition by DEM $(-74 \%)$ and cyanamide $(-95 \%)$, implicating metabolism via mitochondrial aldehyde dehydrogenase. These results suggest that under conditions of enhanced rates of formaldehyde generation there may be a more important contribution made by the mitochondrial aldehyde dehydrogenase towards the overall metabolism of formaldehyde.

It was surprising that DEM, despite depleting the content of GSH in the isolated hepatocyte by about $75 \%$, did not significantly inhibit the oxidation of $0.2 \mathrm{~mm}$ formaldehyde. It would appear that the residual GSH in the hepatocyte (about $1.6 \mu \mathrm{mol} / \mathrm{g}$ wet wt. of liver) is still sufficient to catalyse normal rates of the formaldehyde dehydrogenase reaction. Indeed, the apparent $K_{\mathrm{m}}$ of formaldehyde dehydrogenase for GSH was found to be about $0.09 \mathrm{~mm}$ (Fig. 3). It should be noted that the substrate for formaldehyde dehydrogenase is not free formaldehyde or free GSH but rather is the hemimercaptal adduct (Uotila \& Koivusalo, 1974; Uotila \& Mannervik, 1979). Although the $K_{\mathrm{m}}$ value of $0.09 \mathrm{mM}$ (Fig. 2) must be considered to be approximate, it would appear that low concentrations of GSH are sufficient to saturate the enzyme. Consequently a $75 \%$ depletion of GSH by DEM, which would still leave hepatocyte GSH concentrations of 1-2 mM, may not be sufficient to inhibit formaldehyde dehydrogenase activity. On the other hand, treatment with DEM or phorone in vivo resulted in about a $92 \%$ depletion of cytosolic GSH concentrations, and, under these conditions of a more drastic depletion, formaldehyde dehydrogenase activity was decreased by $40-50 \%$ (Table 4 ). This inhibition is due to cofactor concentrations, since added GSH restores normal rates of enzyme activity. It appears that a critical amount of GSH must be lost before compromising the activity of formaldehyde dehydrogenase.

This work was supported by U.S. Public Health Service Grant AA-03312 from the National Institute on Alcohol Abuse and Alcoholism. We thank Ms. Roslyn C. King for typing the manuscript.

\section{REFERENCES}

Bhatt, H. S. \& Combes, B. (1985) Hepatology 5, 615-621

Billings, R. E. \& Tephly, T. R. (1979) Biochem. Pharmacol. 28, 2985-2991

Boyland, E. \& Chausseaud, L. F. (1970) Biochem. Pharmacol. 19, 1526-1529

Cederbaum, A. I. (1981) Alcohol. Clin. Exp. Res. 5, 38-44 
Cederbaum, A. I., Dicker, E. \& Rubin, E. (1977) Arch. Biochem. Biophys. 183, 638-646

Cinti, D. L., Keyes, S. R., Lemelin, M. A., Denk, H. \& Schenkman, J. B. (1976) J. Biol. Chem. 251, 1571-1577

Deitrich, R. A. \& Hellerman, L. (1963) J. Biol. Chem. 238, 1683-1689

Dicker, E. \& Cederbaum, A. I. (1984a) Arch. Biochem. Biophys. 232, 179-188

Dicker, E. \& Cederbaum, A. I. (1984b) Arch. Biochem. Biophys. 234, 187-196

Dicker, E. \& Cederbaum, A. I. (1985) Biochem. Biophys. Acta 843, 107-113

Eckfeldt, J., Mope, L., Takio, K. \& Yonetani, H. (1976) J. Biol. Chem. 251, 236-240

Goodman, J. J. \& Tephly, T. R. (1971) Biochem. Biophys. Acta 252, 489-505

Jones, D. P., Thor, H., Anderson, B. \& Orrenius, S. (1978) J. Biol. Chem. 253, 6031-6037

Kitson, T. M. (1977) J. Stud. Alcohol 38, 96-113

Koivula, T. \& Koivusalo, M. (1975) Biochem. Biophys. Acta 397, 9-23

Krebs, H. A., Hems, R. \& Tyler, B. (1976) Biochem. J. 158, 341-353

Ku, R. H. \& Billings, R. E. (1984) Chem. Biol. Interact. 51, $25-36$

Lesback, M. E., Petersen, D. R., Collins, A. C. \& Anderson, A. D. (1977) Biochem. Pharmacol. 26, 1151-1154

Received 30 April 1986/10 July 1986; accepted 28 August 1986
Meredith, M. J. \& Reed, D. J. (1982) J. Biol. Chem. 257, 3747-3753

Nash, T. C. (1953) Biochem. J. 55, 416-422

Pietruszko, R., Ferencz-Biro, K. \& Mackerell, A. D. (1985) in Enzymology of Carbonyl Metabolism, vol. 2 (Flynn, T. G. \& Weiner, H., eds.), pp. 29-41, A. R. Liss, New York

Poli, G., Dianzani, M. U., Cheeseman, K. H., Slatter, T. F., Lang, J. \& Esterbauer, H. (1985) Biochem. J. 227, 629638

Richardson, R. J. \& Murphy, S. D. (1975) Toxicol. Appl. Pharmacol. 31, 505-508

Romero, F. J., Soboll, S. \& Sies, H. (1984) Experientia 40, 365-367

Savanije-Chapel, E. M. \& Noordhook, J. (1980) Biochem. Pharmacol. 29, 2023-2029

Siew, C., Deitrich, R. A. \& Erwin, U. G. (1976) Arch. Biochem. Biophys. 176, 638-649

Strittmatter, P. \& Ball, E. C. (1955) J. Biol. Chem. 213, 445-461

Umbreit, W. W., Burris, R. H. \& Stauffer, J. F. (1959) Manometric Techniques, p. 147, Burgess Publishing Co., Minneapolis

Uotila, L. \& Koivusalo, M. (1974) J. Biol. Chem. 249, 7653-7663

Uotila, L. \& Mannervik, B. (1979) Biochem. J. 177, 869-878

Weiner, H., Lin, F. P. \& Sanny, C. G. (1985) in Enzymology of Carbonyl Metabolism, vol. 2 (Flynn, T. G. \& Weiner, H., eds.), pp. 57-70, A. R. Liss, New York 